EGU2020-20379

https://doi.org/10.5194/egusphere-egu2020-20379

EGU General Assembly 2020

(c) Author(s) 2022. This work is distributed under

the Creative Commons Attribution 4.0 License.

\title{
Small but essential in hydrogeochemical cycles: headwater mountain catchments
}

Gaël Le Roux ${ }^{1}$, Marilen Haver ${ }^{1}$, Thomas Rosset ${ }^{1}$, Dirk Schmeller ${ }^{1}$, Laure Gandois ${ }^{1}$, Deonie Allen ${ }^{1,2}$, Stéphane Binet ${ }^{3}$, Anaelle Simonneau ${ }^{3}$, Youen Grusson ${ }^{1}$, Thierry Camboulives ${ }^{1}$, Sabine Sauvage ${ }^{1}$, Didier Galop ${ }^{4}$, Simon Gascoin ${ }^{5}$, and José Miguel Sánchez Pérez ${ }^{1}$

${ }^{1}$ EcoLab, CNRS-University of Toulouse, Castanet-Tolosan, France (gael.leroux@ensat.fr)

${ }^{2}$ Department of Civil and Environmental Engineering, University of Strathclyde, Glasgow, UK.

${ }^{3}$ ISTO, CNRS UMR 7327, Université d'Orléans, BRGM, Orléans, France

${ }^{4}$ GEODE, UMR-CNRS 5602, Université Toulouse Jean Jaurès, Toulouse, France.

${ }^{5} \mathrm{CESBIO}$, Université de Toulouse, CNRS/CNES/INRA/IRD/UPS, Toulouse, France

Despite their small size, headwater catchments of European mountains are essential because they provide many ecosystem services (water quality, energy, tourism, ecological niches).

Based on the hydrological monitoring of a mountain catchment in the central Pyrenees and the extreme conditions encountered in the past and expected in the future, we present scenarios for the evolution of hydrological regimes that will potentially impact the socio-ecological services by high mountain mires, ponds and lakes. In particular, in view of the exacerbated climate change in the high mountains, the shortening of snow season will potentially impact the ecosystem services by the ponds, modifying the minimum water level and/or ecological flow in late spring and early summer. For example, these ponds play an essential role as ecological refuges compared to larger lakes, which are subject to invasions by non-native organisms. Peat pools also play an essential role in the cycling of chemical elements, including carbon. Their modification, their increased intermittency due to more frequent and intense climatic variability will deeply modify, for example, the export of dissolved organic carbon from peatlands.

While it is difficult to accurately predict the future of mountain watersheds, our study aims to identify the key factors for their current roles in biodiversity, water sustainability and in ecological services as well as to determine their future adaptability to other human pressures such as minihydroelectric power plants. 